\title{
The world of work beneath the veil
}

\author{
A. Rhodes \& N. Edge \\ College of Information Systems, Zayed University, United Arab Emirates
}

\begin{abstract}
Encouraging career exploration and developing a path to meaningful graduate employment in an all-women Muslim environment in the face of a range of cultural issues provides challenges for a university in such an environment. This paper reports on experiences from Zayed University in the United Arab Emirates.

In a bold social move, Zayed University was established by the United Arab Emirates government in 1998 as a nationally funded university to meet tertiary education needs solely for national Emirati ladies. Academic degree programs at Zayed University are attempting to prepare these Muslim women for their personal and professional lives in the twenty-first century, and to help shape the future of their country. However, traditional western career development practices need to be tailored to suit the particular cultural needs in this special environment.
\end{abstract}

Keywords: careers, employment, women, muslim, tertiary education.

\section{Introduction}

Zayed University is located in the United Arab Emirates and is a 3000 strong Emirati national all-women student institution. The university, founded only in 1998, was a vision of the founding president of the UAE, Sheik Zayed, to provide a special environment for the education of national women as an important step in educating the UAE nation. Typically, a student at Zayed University is first a generation university family member with women representing seventy five percent of all Emirati nationals in tertiary education institutions. The university is staffed with expatriate faculty from the US, UK, Australia, South Africa and several other countries.

The purpose of this paper is to outline the academic career curricula established at Zayed University in the United Arab Emirates to foster career 
exploration and the development of a path to meaningful graduate employment for females in a Muslim environment. Such women face a range of cultural issues. These are highlighted to provide the reader an accurate portrayal of the challenging environment faced by faculty and staff in preparing these young women for the workplace.

\section{United Arab Emirates (UAE)}

The United Arab Emirates is an amalgamation of the traditional values of the Middle East and the modern technologies of the West. This oil-rich country offers a standard of living that is comparable to the world's most advanced nations, making it one of 20th century's success stories.

United Arab Emirates (UAE) was formed as a federation of seven emirates in December 1971 [1]. The federal capital of UAE is Abu Dhabi, Dubai is the business capital and the city of Sharjah is the UAE's cultural capital. The UAE has capitalized on its convenient location on the trade routes between Asia and Europe by building a fine tradition of being a good host and trading partner since time immemorial. The UAE is a small country (approx. 83,600 sq kms including 200 islands) with a population of around 3.75 million (2002). Approximately $80 \%$ of the population is non-UAE nationals from all over the Arab world, Asia, Europe and Africa. There is also a large contingent of professionals from the US, UK and many other western countries. The official language of the UAE is Arabic though other languages like English, Hindi and Farsi are widely spoken, and the official religion of the United Arab Emirates is Islam.

The UAE economy is strong. The country is a major player the in global oil industry with the Abu Dhabi emirate alone having $10 \%$ of the world's known reserves [1]. Oil and gas production remain the primary source of public revenue but the government has an active strategy of economic diversification with emphasis is on the accelerated development of the finance, trade and services sectors [2]. There has been heavy investment in infrastructure since the establishment of the UAE, and the government is actively encouraging the private sector to participate in further infrastructure development in transport, communications, telecommunications, energy and ports [3]. This sector is also being asked to provide the future employment opportunities for the UAE nationals (male and female) through the existing higher education institutions.

\section{Zayed University}

Zayed University's mission is to prepare Emirati women for meaningful and successful twenty-first century personal and professional lives who will help shape the economic and social future of the UAE. Established in 1998 by the federal government of the UAE, Zayed University has campuses in Abu Dhabi and Dubai, and offers similar programs on both campuses. New campuses in both Dubai and Abu Dhabi will extend student capacity to 5000 by 2008, and the University has been accepted for candidacy by a leading accrediting association in the United States. 
The University has graduated seven classes over three and a half years commencing in 2003. It has instituted, and continues to develop undergraduate programs that focus on learning outcomes and address needs in the UAE employment sectors. The typical entering undergraduate student is a single Emirati female from a primarily Arabic language instruction public school who is a first generation university student. Zayed University's entering students typically wish to be well educated and earn a university degree, but students have mixed intentions regarding employment. Entering students' mothers typically are not employed. Their fathers are primarily employed in government or retired. Both parents normally have limited (or no) experience with higher education.

The University provides a distinctive undergraduate education to meet national objectives and which enables students to fulfill their personal intellectual, social, and career aspirations. Academic programs provide a strong general education component with an emphasis on global awareness, vocationally oriented majors and concentrations.

\section{Zayed University academic model}

Zayed University is based on an international model of higher education. It is organized academically into five colleges of Arts and Sciences, Business Sciences, Communication and Media Sciences, Education, and Information Systems, with the primary language of instruction being English.

\subsection{Readiness program}

The primary purpose of the Readiness Program is to prepare students for academic study in English at Zayed University. When students enter the University, they are placed in the appropriate level of the program according to their score on the Common English Proficiency Assessment (CEPA) test. Students who need to increase their ability in English must complete English courses which develop their abilities to a proficiency level at which they can begin their baccalaureate studies. Students must meet these outcomes before they can progress to the next level.

Each English Readiness and pre-major student is assigned an advisor from the Advising Centre, who tracks her academic progress and assists her in meeting academic goals. The advisor assists the student in adjusting to university education, helps her to learn academic and personal success skills, and instructs her in the Zayed University Academic Model.

\subsection{Colloquy on Integrated Learning (COIL)}

All students in the eight semester baccalaureate program enrol in the Colloquy on Integrated Learning, the core curriculum of the university. A similar intellectual experience is therefore shared by all students. As students undertake work in their major field of study during the fourth semester, they select courses from two integrated menus that contribute both to the Colloquy's learning goals 
and, in some cases, to the learning goals in the student's major program as well. This interdisciplinary general education curriculum continues through the third year of the baccalaureate program, when students select two integrated menu courses. These courses mark the culmination of the Colloquy program and its emphasis on facilitating student success by developing students' critical engagement with the world.

\section{Cultural challenges}

There is a wide range of cultural factors at work in a university that is allwomen, nationals only, based on an Islamic society, and located in an Arab country that is part of the Gulf region. Added to that mix is a largely western male faculty, teaching a western-based curriculum, and using teaching techniques and approaches normally more associated with western-style universities. Many of the values, methods and assumptions made by faculty in this environment are either invalid, inappropriate or, at best, only useful in part. Arab and Islamic culture, family values and heritage, the role of women, and local UAE social norms are some of the complex cultural elements that combine to present western faculty, particularly new arrivals, with a range of bewildering challenges.

\subsection{Veiled students}

Students, as Emirati nationals and Muslim women, come to university in traditional UAE dress. Over, in most cases very expensive and highly fashionable, normal western clothes the students wear a full-length lightweight black 'overcoat' called an abaya. Each student also wears a head scarf or shayla which can be completely drawn over the face. The 'face mask' or burka is never seen on campus, but some students are 'veiled' with only their eyes visible. A very small number of students also cover their hands with black gloves. Outside of the university students are extremely careful about being covered, but abayas and shaylas are often only loosely worn as students move around campus, though the appearance of a male faculty can cause a hurried cover-up for some ladies. How and what a student wears will often reflect family values, from extremely conservative to surprisingly liberal, but modesty is expected of all on campus, students and faculty alike. Many students become engaged, married, or mothers during their time at university. In some cases, marriage can come for these ladies at very short notice.

\subsection{Female-only campus}

For most western faculty the student's clothing and modest behavior is perhaps the first and most visible sign, along with the regular call to prayer, of the Islamic culture. But this culture is far more pervasive for normal university life in this environment. The campus is a closed campus with strict access restrictions and is security guard controlled. All students are logged into and out of campus via an electronic system. Parents have the right to know the 
whereabouts of their daughters at all times, and strict parental, or husband, permission rules are enforced for off campus activities. When off campus, students are closely chaperoned by faculty to ensure permission conditions are strictly met.

\subsection{Role of the family}

In all this, there is much variation in student attitudes, expectations and behaviours. Some students are far more relaxed with male faculty while others are less comfortable, and this most likely reflects family values and attitudes. Family origin and rank also impact the student learning environment. Some national family names and histories reach back hundreds of years and, as such, can be an intimidating influence on some students not from that background. Many national women in the UAE are home bound with few venturing far from home and almost never without a family male chaperone. Many have not travelled widely, especially overseas, and are exposed mainly to Arab media. Gender stereotyping [5] is prevalent with many students reporting that families see business and education, and not information technology, as appropriate professions for women. And yet, information technology enables an interesting contrast to the confined world of UAE women. The Internet, heavily censored by the UAE government [6], provides these information technology literate students with a freedom unknown to their mothers and perhaps not even realized by their families today. Using the anonymity of the Internet many students are able to chat with people all over the world and to maintain a level of contact and freedom with family and friends denied their mothers.

\subsection{Employment and the family}

The influence of the family extends also to the employment prospects of the students. Examples abound where families, including husbands, uncles, brothers, refuse the students the opportunity to take internships or apply for jobs in mixed male/female work environment or environments where they cannot remain veiled. In some instances, students have no prospect of employment because of family objections. And in other cases, especially for the more wealthy families, employment opportunities are unattractive in terms of working hours, holiday freedoms and salary. A job can be impossible because of the necessity to travel. But, in all this again, there is much variation. Some families are very supportive of their daughters in seeking a profession and joining the workforce. And still others encourage a small number of students to travel abroad, alone, to pursue postgraduate studies. Many students have little first hand knowledge of even the most common and simple business practices because transacting all family business is normally the domain of the male members of the family. This lack of worldliness becomes evident in the learning situation where simple business situations need lengthy and detailed explanations that would be totally unnecessary in western universities. Most female students have no opportunity for part-time work, to develop a work culture or to build aspirations to follow a profession. There are few female role modes in business and government, and 
most female students are denied the opportunity for postgraduate studies because of cultural limitations.

\section{Employment in the curricula}

In light of the cultural challenges discussed in the preceding section of this paper, encouraging students to think about employment is a challenging task for Zayed University, both for academics and staff in Careers Services. A fiercely competitive job market for entry-level positions, expectations, pressures and attitudes of families, a lack of understanding of the job market, and little knowledge of the world of work makes facing the employment question a daunting task for most students. In the first entry-level course to any of the majors (a CPS125 course), careers relating to the disciplines of that major feature heavily. In all courses of any major faculty attempt to relate the course materials to practice and to the employment question. A key component in any major relating to the employment question is the internship course. Faculty involved with this course have a particularly important role to prepare, guide and assist students to a far greater degree than might be expected in western universities. Weekly reports are carefully collected from each student and at the end of their internship students are required to reflect on their internship both as a professional and personal experience, to address employment questions and to begin the process of finding a position. To witness the increase in the level of professional and personal confidence of the students returning from their internship is extremely encouraging for the faculty involved. And many students, buoyed by their internship experience, are motivated to being the difficult task of seeking employment.

The internship, to be discussed further in section 6.2, is the culminating career exploration moment. Most of the important groundwork in developing individual career aspirations is done is semesters 1 and 2 as part of the COIL. A specific set of career focused courses has been set up for this objective.

\subsection{Careers curricula sequence}

In the colloquy program there are three courses COL120 (semester 1), COL105 and CPS125 (concurrently in semester 2) all students undertake to assist them in developing personal careers goals. These career goals will be developed further through the students undertaking of an appropriate college major for her baccalaureate.

COL120 and COL105 provide the introduction and support to the most important component of the careers curricula sequence (CPS125). This is shown in the appendix. Note the before and after interaction with readiness and advising respectively. The role of CPS 125 is discussed in the next section. A brief outline of COL120 and COL is also provided. 


\subsubsection{CPS 125 and the career education curriculum}

The CPS 125 Menu plays a key role in Zayed University's Career Education Curriculum for its young women.

Through placing the field of study in a comparative framework, the faculty members from the various colleges not only develop a student's understanding of the discipline; they also build knowledge of potential careers that are open to her in the UAE. There are seven CPS 125 courses belonging to the five colleges corresponding to the seven disciplines of the university: Information Systems, Business Sciences, Education, Art and Design, Communication and Media Sciences, Social and Behavioural Sciences, Health Sciences. The UAE has a strong need for professionals in these fields in both the government and private sectors. Each of the CPS courses is intended to work in concert with Readiness Level 6 and 8 and with COL 120, 105 and Advising 201 (Appendix).

A CPS125 course places a particular discipline in a comparative global context through exploring the way in which study in this field translates into career contexts in various nations in the world. Through placing the profession in a comparative context, the course not only assists students in their exploration of a possible field of study, it also increases their general knowledge of the world and its professions. This is very important since many (if not all) students come to Zayed University with a marked lack of general knowledge of the world and the career opportunities that exist for them in all sorts of organisations.

An important component of a CPS125 course is the Careers Exploration Project (CEP). The primary objective of the CEP is to align the goals of the CPS course with the Career Education Curriculum that extends from Readiness to Internship. Conceptualized as a developmental process, the curriculum as a whole combines the development of a student's self-awareness with an increased capacity to be effective in the professional world for which her studies prepare her. The shared goal of the Careers Exploration Project in all CPS courses is to enable students to gather and analyze information about the specific professional environment in the UAE related to the discipline under study.

As previously mentioned, COL120 and COL105 serve support roles to the CPS125 courses. Very briefly, these courses respectively cover:

6.1.1.1 COL120 - "Ways of Knowing" The content addresses contemporary issues facing cities around the world. Separate modules explore topics such as "Addressing Social Issues in the City" and "Cities as Cultural Centres". Within each of these topics, individual cities will be examined and the role particular professions play in addressing civic issues are highlighted. This enables students to see the connection between the seven academic disciplines, majors and careers and how these disciplines are applied in real-life situations. Throughout the course, students demonstrate understanding through participation in authentic tasks, rather than an emphasis on factual recall and content knowledge.

6.1.1.2 COL105 - "Career Exploration" The content focuses on three main areas of exploration: world of work exploration, career exploration and 
individual/self-exploration. Specifically this course targets the following objectives:

- $\quad$ To investigate issues relevant to students as female UAE nationals and as individuals (including Emiratization, working mothers, glass ceilings, career paths, transferable skills, motivation to work); [Emiratization is the process of gradually integrating trained and qualified UAE nationals into the workforce (particularly the private sector) by replacing part of the existing expatriate labour force];

- To gain awareness of the realities of the world of work for young female graduates in the UAE.

- To gain awareness of the realities of particular careers available to $\mathrm{ZU}$ graduates.

- Use self-assessment tools to explore factors relating to career choice: personality, abilities, interests, values, experiences, constraints and opportunities.

\subsection{Internship}

Once a student has left the COIL program and progressed towards the end of her major studies in her baccalaureate she is now prepared for the major component of her careers education learning experience, her internship.

Internships at either private or government sector workplaces provide students with career related, experience centered professional work. The tenweek internship also allows potential employers the opportunity to see students in action. Students normally enter their internship during their final semester as part of their major. Initially, the internship course addresses relevant professional development issues such as placement negotiation, professional conduct and dress, work ethics, interpersonal communication and initiative. Each college is responsible for its internship program, and works in collaboration with students and community representatives to define the purpose, experiential learning outcomes and guiding goals for each intern. Student progress is measured by achievement of clearly defined learning outcomes. At the close, students make a final report to their college faculty, in which they perform a structured reflection and critical review of their experience that helps them to make better, more cognizant career decisions upon graduation.

\subsection{Zayed University graduate employment}

On graduation students face an uncertain future. Some are denied employment by cultural circumstance, others by lack of opportunities, and others faced with a highly competitive employment environment. Students graduating face strong completion from expatriates, especially in the private sector. Most graduates seeking employment, however, are attracted to the shorter hours, higher salaries, more holidays, and sometimes, special women-only work environments of government departments. Emiratization of the private sector is addressing the 
situation in some small degree but family and cultural restrictions can deal a crushing blow to a student's career plans. In some cases if a family name is not prominent in a student's target workplace she may not be allowed by her father, brother or husband to work in that organization.

To balance what must look like a gloomy picture it must be said that many students do find rewarding employment. In fact since the first graduating class of Zayed University students in 2003 some $67.2 \%$ of graduates have found fulltime employment in their discipline. Some students are able to exploit the family connections while others simply stand out from the crowd with exceptional skills and presence. All students, even those unsuccessful so far in finding employment, are highly motivated, hard working, conscientious and very determined. Some of these students return to Zayed University as successful role models/mentors to encourage new students to follow in their footsteps.

\subsection{Work and the different gender perspectives}

As mentioned in section 1, females comprise $75 \%$ of undergraduate enrolments in the UAE. Interestingly, almost all females enrolled do so of their own choice for many reasons - a sense of empowerment, independence, ambition, desire to learn about the world by being allowed out of their home, a desire to work, a strong desire to establish a social network beyond the home/family environment, an opportunity to exercise and develop their minds. These motivating factors for females should not be underestimated in explaining the high percentage of females in undergraduate academic programs. In the West these factors are often taken for granted - not so in the UAE or other similar Muslim countries. They are critical factors for these women. According to 2004 data [8] 85\% of females entering higher education transition through to graduation. Conversely, this figure is only $54 \%$ for males. Recall that $75 \%$ of tertiary students are female. These figures indicate that over time there will be a very large number of tertiary qualified females and a relatively small number of tertiary qualified males. What effect this will have on the cultural fabric of UAE society in the future will indeed be interesting. How will the roles of men and women in this Muslim society be affected by this phenomenon? These questions make for interesting follow-up research in the medium term.

Why then are there so few UAE males relative to UAE females voluntary enrolled in undergraduate programs? One answer lies in the fact that many males finish high school and enter comfortable, secure, well-paid jobs in the government sector, particularly the armed services and police. In these sectors tertiary study is a conditional part of their employment. It is estimated that this group makes up $60 \%$ of UAE males enrolled in undergraduate programs. After a short period (by Western standards) of employment (10 to 15 years depending on the sector) they can retire and receive generous retirement benefits for the rest of their lives (in addition to any income from companies they may be sponsoring this is discussed next).

Another answer to this question relates to how a company is permitted to conduct a business in the UAE. Each business is required to have a UAE national sponsor before it can be legally permitted to trade its services or products. The 
sponsor is paid a yearly fee to keep this sponsorship current. A sponsor is almost always male (a female needs male permission - this rarely occurs) and this person can sponsor numerous companies therefore generating a healthy remuneration each year. The net effect of this is the lack of motivation for education generally, and in particular, tertiary education among the male population of the UAE. On the other hand, females have very strong motivational factors for them to enter the tertiary sector, and it can be seen that are being successful.

In conclusion, Zayed University is a unique all-women Muslim university in the United Arab Emirates with the goal of educating and preparing first generation Emirati females to take their place in the workplace. Zayed University has developed and implemented an effective careers education curriculum spanning pre-baccalaurate admission through to a culminating internship program to effect this goal. With almost $70 \%$ of graduates fully employed, the university is well on its way to achieving its goal of $90 \%$ employment for its graduates.

Working at Zayed University is not without its challenges. But neither it is without its rewards.

\section{References}

[1] UAE Government, (n.d.) Retrieved Oct 22, 2005 http://www.uae.org.ae.

[2] United Arab Emirates Yearbook 2004, (n.d.) Retrieved Oct 29, 2005 http://www.uaeinteract.com/useint misc.

[3] UAE Government, (n.d.) Retrieved Oct 22, 2005 http://www.uae.gov.ae/ Government.

[4] United Nations Development Programme (UNDP), The Arab Human Development Report 2002 - Creating Opportunities for Future Generations, 2002.

[5] McLoughlin, L.A. (2005), "Spotlighting: Emergent Gender Bias in Undergraduate Engineer Education", Journal of Engineering Education, ASEE, Oct 2005, vol. 94, no. 4.

[6] OpenNet Initiative, (2005). Internet Filtering in the United Arab Emirates in 2004-2005: A Country Study Retrieved Oct 29, 2005 http://www.openinitiative.net/studies/uae.

[7] UAE Ministry of Education \& Youth, Education Vision 2020 - Pillars, Strategic Objectives, Projects and Implementation Programs for UAE Education Development, 2000.

[8] UAE Ministry of Education, Higher Education Graduation Report 2004, National Placements and Offers, 2005. http://www.napo.ae/. 


\section{Appendix: colloquy careers education curriculum}

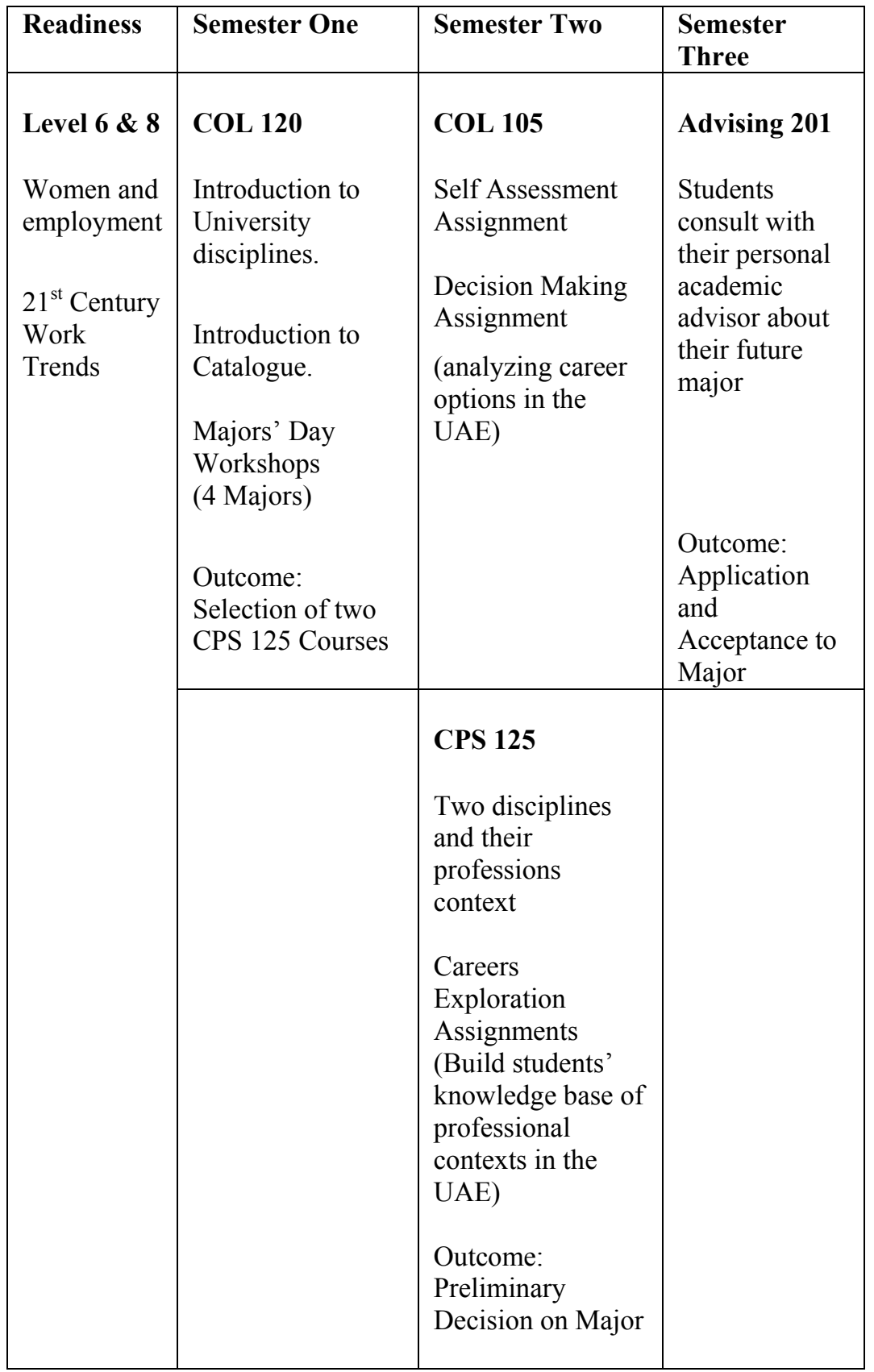

